\title{
Experimental Study on the Behavior of Tension Member Under Rupture
}

\author{
M. Rajendran ${ }^{1, a^{*}}$, V. Gnanasundar ${ }^{1, b}$, C. Aravindhan ${ }^{1, c}$ \\ ${ }^{1}$ Department of Civil Engineering, Bannari Amman Institute of Technology, \\ Sathyamangalam, Tamil Nadu, India - 638401 \\ a*rajendranm@bitsathy.ac.in, bgnanasundar@bitsathy.ac.in, caravindhanc@bitsathy.ac.in
}

\begin{abstract}
Keywords: Tension Member, Hot-Rolled Steel Sections, Rupture Strength, Lap Joint, Bolted Connections, Pitch, Gauge, End and Edge Distance
\end{abstract}

\begin{abstract}
A steel structure is naturally lighter than a comparable concrete construction because of the higher strength and firmness of steel. Nowadays, the growth of steel structures in India is enormous. There are so many advantages in adopting the steel as structural members. Almost all high-rise buildings, warehouses \& go-downs are steel structures and even some of the commercial buildings are made of steel. Tension members are the elements that are subjected to direct axial load which tends in the elongation of the structural members. Even today bolted connections play a major role in the connection of hot rolled structural steel members. In this experimental study the behavior of tension members (TM) such as plates, angles \& channels have been studied under axial tensile force. There is strong relation between pitch and gauge (with in the specified limit as per IS 800:2007) in determining the rupture failure plane. In this study we intensively tested the behaviour of TM for different fasteners pattern by changing the pitch, gauge, end \& edge distance and by adopting the different patterns or arrangements of bolted connection in it.
\end{abstract}

\section{Introduction}

Steel is a structural member which is extensively used in industrial buildings, warehouse, residential buildings as a tensile member. Due to its tensile property, industrial buildings and warehouses are completely constructed with steel. When using steel entirely in buildings, duration of the construction can be significantly reduced [1]. In future, usage of steel in construction is going to be increased. So, we are determining tensile strength [2] of steel by testing the steel as per IS standard with varying connections such as chain pattern, zig-zag pattern, diamond pattern with varying pitch and gauge distance.

Cold-formed structural steel plates of thickness $1.5 \mathrm{~mm}$ can be lap joined with bolted connections which are designed as per IS 800-2007[3]. The final load-supporting potential connection considered to feasible failure modes, which includes bearing, give-up tear-out, bolt shear, block shear [4], rupture, etc... fy=550MPa, G300 (fy=300MPa) sheet plates were inspected. From the result we concluded that both the Australian/New Zealand (AS/NZS 4600, "cold-shaped metallic" and the Iron and metallic Institute (AISI, "1996version" 1997) layout requirements cannot be used to expect the failure modes of skinny-sheet-steel bolted connection loaded in shear.

Commonly, the internet-phase fracture is predicted looking at outcomes displayed that bearing distress in the sheet metal is the controlling mode. Likewise, suggestions are made regarding themodern-day method to become aware of the bearing-failure modes [5]. Furthermore, a detailed discussion is equipped with the test data that being used inside the improvement of the AS/NZS 4600 ("cold-shaped steel" 1996) [6] and AISI ("1996edition" 1997) design equations used for connections. Several different types of bolted connections, including shear connections at the ends of coped beams, tension member connections, and gusset plates, can be regulated by a block shear 
failure [7]. A tension force in the splice causes the flange plates to deform in normal loading conditions [8]. bolted connections are often favoured over other forms of mechanical fasteners, such as split rings [9].

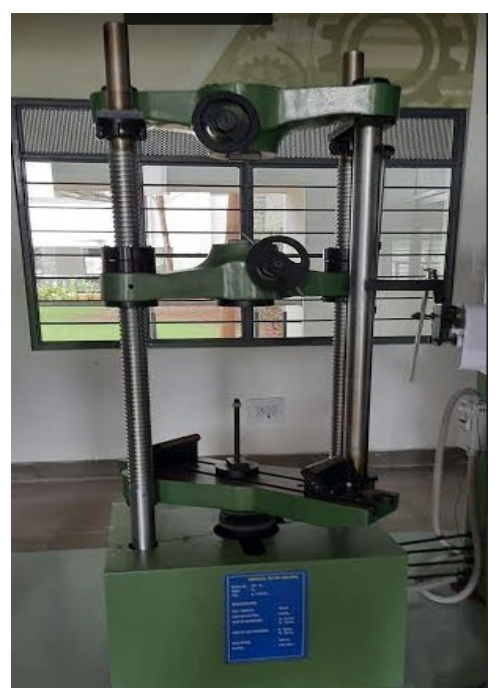

Figure 1.Universal Testing Machine

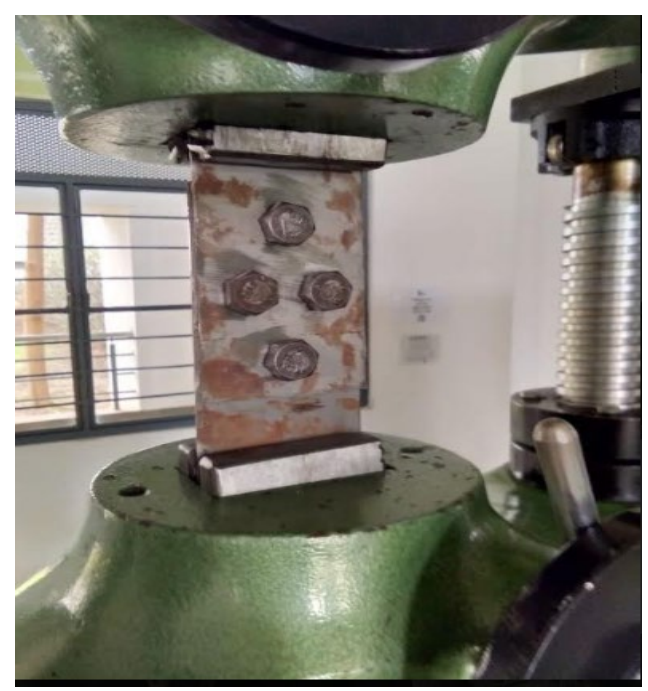

Figure 2.Testing of Metal Plate

\section{Materials Used}

1. Thin Metal Sheet of thickness $1.5 \mathrm{~mm}$

2. Fastener of size $12.75 \mathrm{~mm}$

3. Driller for holes

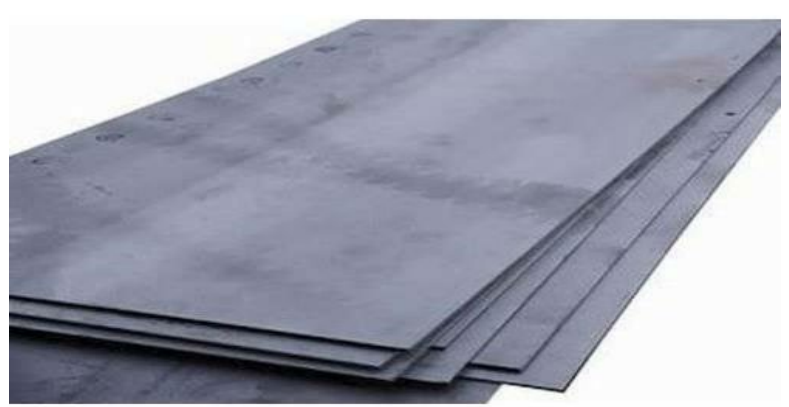

Figure 3.Thin Metal Sheet of $1.5 \mathrm{~mm}$ thick

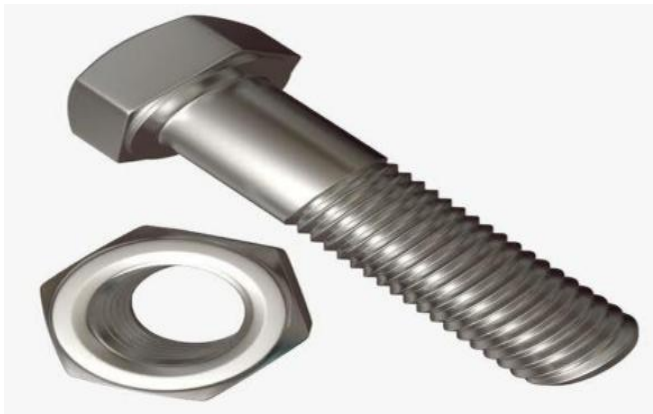

Figure 4.Fastener of $12.75 \mathrm{~mm}$

\section{Thin Metal Sheet}

Thin metal sheet is used because of its many advantages like it is resistance to corrosion and prone to all weather conditions. The sheet metallic fabrication is idealized for used in today's environment in which various weather and climatic conditions and it is more durable. The sheet metals are sufficient to resist pressures and it is easy to make a drill on it. The thin sheet metals of thickness $1.5 \mathrm{~mm}$ are designed on the length of $120 \mathrm{~mm}$ and width of $75 \mathrm{~mm}$ respectively (Refer with: Figure 3). The thin metal sheet is designed and cut to the required size for the different patterns of bolted arrangements. 


\section{Fastener}

The fasteners used in this project are the Mild Steel fasteners of diameter $12.75 \mathrm{~mm}$.(Refer with: Figure 4)

\section{Methodology}

Preparation of bolted metal sheet-Lap Joint

Initially, the thin metal sheet of thickness $1.5 \mathrm{~mm}$ are purchased in market and cut for our desired length and width to do our experiment purpose. Then after cutting in suitable size and width, do measures to make the lap joint for the metal plates. To ensure twice it was placed in a current position to make holes in it. The bolt arrangement will play a major role in it.Totally there are nine plates, the pattern consists of zig-zag of 3 sets, diamond of 3 sets and the finally the bolt are arranged as chain pattern.After placing, mark with chalk piece for putting holes to hold the fastener in it.By the help of drillers, we need to drill the hole after tightly fix in a drilling machine then turn on the drilling machine to make the hole. After the drilling was done ensure that the fastener will fix in it and finally place the fastener and tight it as a lap joint connection.

\section{Testing of Bolted Metal Sheet - Lap Joint}

After the metal plates with lap joint get ready, it is supposed to test in the lab for identifying the failure modes of the fastener and the bolt arrangement to check where it gets failed, whether it is safe or unsafe and all. The machine used for testing these plates is named as Universal Testing Machine (UTM) (Refer with: Figure 1)which can withstand up to40 tones. Initially, turn on the UTM and push the up bottom or down button to make space to fit the thin metal bolted lap joint sheet in the machine. After got placed in the machine we need to tight it up and down manually (Refer with: Figure 2). Then we are supposed to give load for that particular metal bolted sheet and carefully note the reading when the needle in the meter reaches the value and suddenly get back.We need to take the reading, when the needle starts from the point back to zero. This value is known as the edge value of the bolted connection. Then the same procedures are repeated for the further designed bolted metal plates of lap joint.Then after completing the tests for all the nine plates compare and conclude the value.

$$
\begin{array}{ll}
\text { Thickness of a Bolt } & =15 \mathrm{~mm} \\
\text { Diameter of a Bolt } & =12.7 \mathrm{~mm} \\
\text { Area of a Single Bolt } & =126.61 \mathrm{~mm}^{2}
\end{array}
$$

Shear Calculation:

$$
\begin{aligned}
& \quad \mathrm{A}_{\mathrm{nb}}=0.8 * \mathrm{~A}_{\mathrm{sb}} \\
& =100 \mathrm{~mm}^{2} . \\
& \mathrm{Vn}_{\mathrm{sb}}=400 / \sqrt{ } 3 *(1+100) \\
& =18.656 \mathrm{KN} \\
& \text { End / Edge Distance: } \\
& \quad \text { Minimum Distance }=1.5 * \mathrm{~d}_{\mathrm{o}} \\
& =21 \mathrm{~mm} . \\
& \text { Pitch \& Gauge Distance: } \\
& \quad \text { Minimum Distance }=2.5 * \mathrm{~d}_{\mathrm{o}} \\
& =35 \text { mm. } \\
& \text { Maximum Distance }=16 \mathrm{t} . \\
& \text { Single Bolt Value }=16.154 \mathrm{KN} \\
& \text { 4 Total Bolt Value }=32.308 \mathrm{KN} .
\end{aligned}
$$




\section{Result and Discussion}

Provided Edge Distance as per IS 800:2007:

Table 1: Edge distance provided as per IS 800:2007 recommendations.

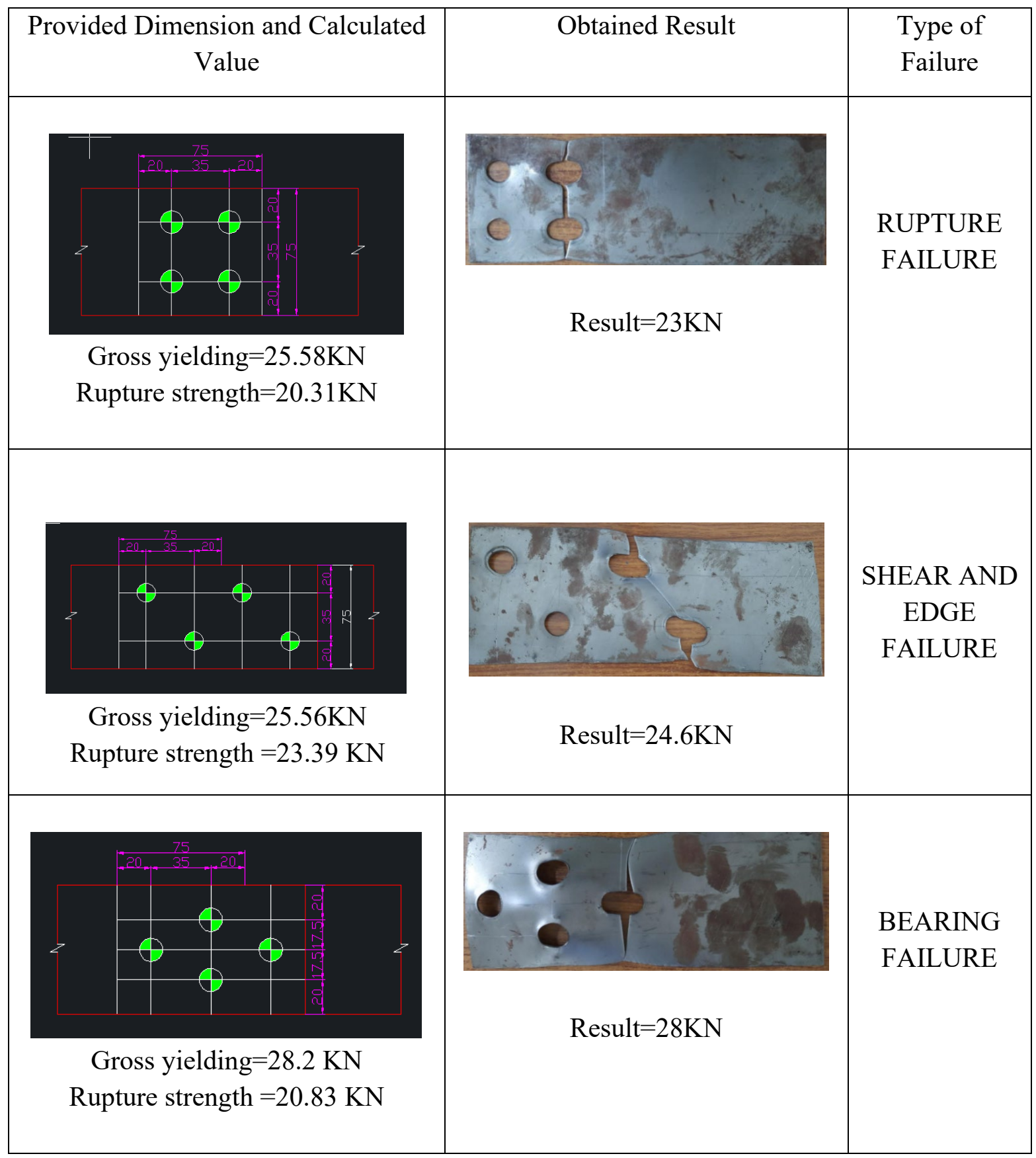

The testing is done in Steel Plates with the edge distance as same as codal recommendations. In Chain Patten as per codal recommendations the edge distance is provided as $20 \mathrm{~mm}$, in that a calculated Tensile Strength is $25.58 \mathrm{KN}$. But, in tested it occurs a failure at $23 \mathrm{KN}$ and a rapture failure is occurred. Next, In Zig- Zag Pattern edge distance is $20 \mathrm{~mm}$, in that a calculated Tensile Strength is $23.34 \mathrm{KN}$. But, in tested it occurs a failure at $24.6 \mathrm{KN}$ and a Shear and Edge failure is 
occurred. Next, In Diamond Pattern edge distance is $20 \mathrm{~mm}$, in that a calculated Tensile Strength is $20.81 \mathrm{KN}$. But, in tested it occurs a failure at $28 \mathrm{KN}$ and a Bearing Failure is occurred (Refer with: Table 1).

\section{Reducing Edge Distance}

Table 2: Reduced Edge distance than recommended by IS 800:2007.

\begin{tabular}{|c|c|c|}
\hline $\begin{array}{l}\text { Provided Dimension and Calculated } \\
\text { Value }\end{array}$ & Obtained Result & $\begin{array}{l}\text { Type of } \\
\text { Failure }\end{array}$ \\
\hline $\begin{array}{l}\text { Gross yielding }=27.48 \mathrm{KN} \\
\text { Rupture strength }=22.48 \mathrm{KN}\end{array}$ & Result $=21.8 \mathrm{KN}$ & $\begin{array}{l}\text { RUPTURE } \\
\text { FAILURE }\end{array}$ \\
\hline $\begin{array}{l}\text { Gross yielding }=22.37 \mathrm{KN} \\
\text { Rupture strength }=20.14 \mathrm{KN}\end{array}$ & Result $=22.6 \mathrm{KN}$ & $\begin{array}{l}\text { SHEAR } \\
\text { AND EDGE } \\
\text { FAILURE }\end{array}$ \\
\hline \begin{tabular}{l}
$z$ \\
\cline { 2 - 3 } \\
\cline { 2 - 3 }
\end{tabular} & Result $=25 \mathrm{KN}$ & $\begin{array}{l}\text { BEARING } \\
\text { AND } \\
\text { SHEAR } \\
\text { AND EDGE } \\
\text { FAILURE }\end{array}$ \\
\hline
\end{tabular}

The testing is done in Steel Plates with the reduced edge distance of $15 \mathrm{~mm}$. In Chain Patten the calculated Tensile Strength is $22.48 \mathrm{KN}$. But, in tested the rapture failure occurred at $21.8 \mathrm{KN}$ and the plates gets a buckled. In Zig- Zag Pattern edge distance is $15 \mathrm{~mm}$, in that a calculated Tensile Strength is $20.14 \mathrm{KN}$. But, in tested it occurs a failure at $22.6 \mathrm{KN}$ and a Shear and Edge failure is 
occurred. Next, In Diamond Pattern edge distance is $15 \mathrm{~mm}$, in that a calculated Tensile Strength is 17.51 KN. But, in tested it occurs a failure at $25 \mathrm{KN}$ and a Bearing Failure is occurred (Refer with: Table 2).

Increasing Edge Distance

Table 3: IncreasedEdge distance than recommended by IS 800:2007.

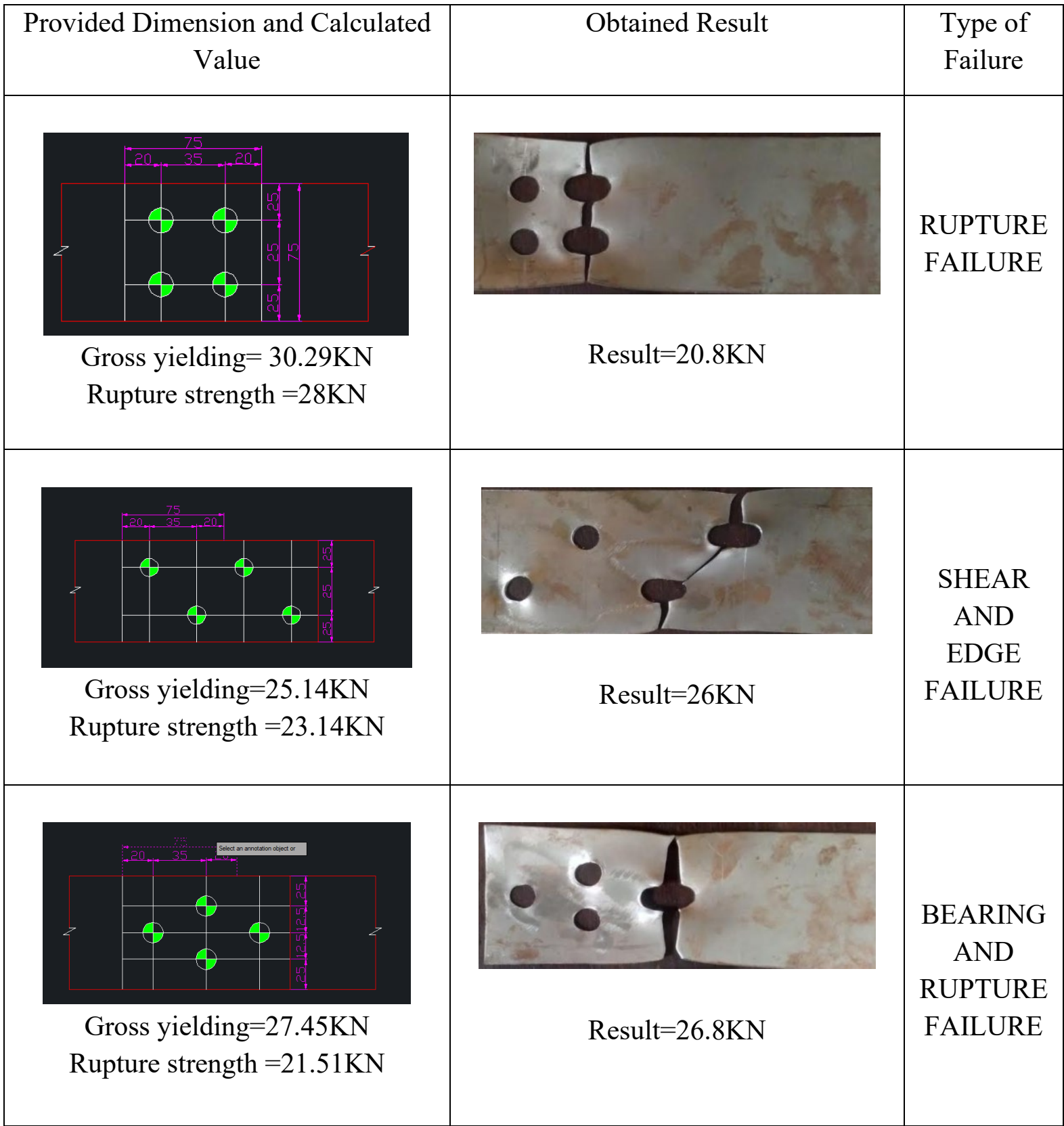

The testing is done in the Steel Plates with the increased edge distance of $25 \mathrm{~mm}$. In Chain Patten the calculated Tensile Strength is $21.48 \mathrm{KN}$. But, in tested it occurs a failure at $20.8 \mathrm{KN}$ and a rapture failure is occurred. In Zig- Zag Pattern edge distance is $15 \mathrm{~mm}$, in that a calculated 
Tensile Strength is $23.14 \mathrm{KN}$. But, in tested it occurs a failure at $26 \mathrm{KN}$ and a Shear and Edge failure is occurred. In Diamond Pattern edge distance is $20 \mathrm{~mm}$, in that a calculated Tensile Strength is $21.51 \mathrm{KN}$. But, in tested it occurs a failure at $26.8 \mathrm{KN}$ and a Bearing and Rupture failure is occurred (Refer with: Table 3).

\section{Conclusion}

As the experiment is done in 3 different methods by changing the edge distance from the reducing and increasing and same as the code provided. in that experiment and come to conclusion that by changing the edge distance in increasing the edge distance in zig zag connection obtained a higher strength then the code provided by its failure under a buckling an edge plates is gets a tear and got failure it is not recommended while designing a connection. In other connections are obtaining a strength less than the code provided. So, edge distance provided in code is better for designing a connection.

\section{References}

[1] Huajie Wen, Hussam Mahmoud, Simulation of block shear fracture in bolted connections, Journal of Constructional Steel Research, 2017, Volume 134, pg 1-17.

https://doi.org/10.1016/j.jcsr.2017.03.006

[2] IS 800-2007 Indian Standard GENERAL CONSTRUCTION IN STEEL - CODE OF PRACTICE (Third Revision).

[3] Matthew D. Elliott, Lip H. The, Aziz Ahmed, Behavior and strength of bolted connections failing in shear, Journal of Constructional Steel Research, Volume 153, February 2019, pg 320-329. https://doi.org/10.1016/j.jcsr.2018.10.029

[4] Bo Yang, Kang Hai Tan, Experimental tests of different types of bolted steel beam-column joints under a central-column-removal scenario, Engineering Structures 54 (2013), pg 112-130. https://doi.org/10.1016/j.engstruct.2013.03.037

[5] Lip H. The, Mehmet E. Uz, Effect of loading direction on the bearing capacity of cold-reduced steel sheets, Journal of Structural Engineering, Volume 140, Issue 12, December 2014. https://doi.org/10.1061/(ASCE)ST.1943-541X.0001107

[6] AS/NZS 4600:1996, Dec 2005, cold-formed steel structures.

[7] Jagdish R. Dhanuskar, Laxmikant M. Gupta, Experimental Investigation of Block Shear Failure in a Single Angle Tension Member, International Journal of Steel Structures, 2020, pp 847-859

[8] S. Willibald, J. A. Packer, R. S. Puthli, Experimental study of bolted HSS flange-plate connections in axial tension, J. Struct. Eng., 2020, Volume 128, pp 328-336. https://doi.org/10.1061/(ASCE)0733-9445(2002)128:3(328)

[9] N. Gattesco, I. Toffolo, Experimental study on multiple-bolt steel-to-timber tension joints, Materials and structures, 2004,Volume 37, pp 129-138. https://doi.org/10.1617/13724 